\title{
Study of Adaptation to Base of CSG Dam
}

\author{
J. Ma ${ }^{1, a}$, L.Q. Yang ${ }^{2, b^{*}}$ and Y. Wang ${ }^{2, c}$ \\ ${ }^{1}$ School of Automation and Electrical Engineering, University of Jinan, Jinan, Shandong province, \\ China 250022 \\ ${ }^{2}$ School of Civil engineer and architecture, University of Jinan, Jinan, Shandong province, China. \\ 250022 \\ acce_maj@ujn.edu.cn, bcea_yanglq@ujn.edu.cn, ccea_wangy@ujn.edu.cn
}

Keywords: CSG dam; base; adaptation; key place.

Abstract. CSG material was used in low damand embankment in aboard and home. Considering of the new building material and economic aim, the study of adaptation to base of CSG dam is very important. The CSG material and base was looked as continuous material. The ratio of CSG's elastic model to base's was used to indicate the difference of base. YUMAOHONG twin shear stress criterion was used as criterion function. Many times FEM calculation was done. The result shows the relation of stress, displace and criterion value to the ratio of CSG and base's elastic model respectively. The key place (or danger place) was founded. Through anglicizing the stress, displace and criterion value of key place, some useful conclusion was draw.

\section{Introduction}

CSG (Cemented Sand and Gravel) is a kind of new material in 1976 J.M. Raphael proposed , which is to add a cementations material and water to the riverbed gravel or excavation waste material these easy to find rocky substrate material which is in the vicinity of the dam site, And then mixing with a simple device obtained by mixing ${ }^{[1-3]}$. CSG material properties is between rockfill material and concrete performance, compared with rockfill material has better strength and resistance to erosion, overflow capacity, but compared with the concrete its strength, consistency and impermeability worse. CSG technology has local resources, make full use of local materials and conventional construction equipment, and shorten the construction period, the advantage of reducing the project cost. The technology came not long, is currently used for the construction of the cofferdam, silt detention dams and other small temporary buildings. Since it is mainly used for temporary structures, economic considerations, and often do not want to do too much into the foundation, therefore, it is necessary to study the situation of the effects of the different foundation of the dam. As is well known, the displacement field and stress field of the dam and the foundation is a function of the ratio of elastic modulus of dam and foundation. Therefore, according to the dam and foundation elastic modulus ratio is different, research dam and foundation displacement field; stress field changes can achieve the research purposes of adaptability of CSG dam foundation.

\section{Strength Criterion}

CSG dam has cement and other cementations materials, and therefore should not analysis by granular mechanics, and shall, should be a Continuous physical science analysis .Foundation also analyzed as a continuous body, Strength criterion of dam and foundation adopt Yu Maohong twin shear strength criterion ${ }^{[4]}$ :

When $\sigma_{2} \leq \frac{\sigma_{1}+\alpha \sigma_{3}}{1+\alpha}$

$$
Z=\sigma_{1}-\frac{\alpha}{2}\left(\sigma_{2}+\sigma_{3}\right)-f_{t}
$$

When $\sigma_{2} \geq \frac{\sigma_{1}+\alpha \sigma_{3}}{1+\alpha}$

$$
Z=\frac{1}{2}\left(\sigma_{1}+\sigma_{2}\right)-\alpha \sigma_{3}-f_{t}
$$


Where $\alpha=f_{t} / f_{c} \cdot f_{t} 、 f_{c}$ are Uniaxial tensile and compressive strength of the material.

\section{Case study}

A 100 meters high dam, On the downstream dam slope 1:0.6, The calculation condition is dead weight and crest flush hydraulic, the grade of dam material is equivalent to concrete $\mathrm{C} 10$, elastic modulus $\mathrm{Ec}=1.75 \times 104 \mathrm{MPa}$, material density $24 \mathrm{kN} / \mathrm{m} 3$, Standard compressive strength is $6.7 \mathrm{MPa}$, standard tensile strength is 0.9 MPa. The finite element meshes of the Computational objects shown in Fig. 1.

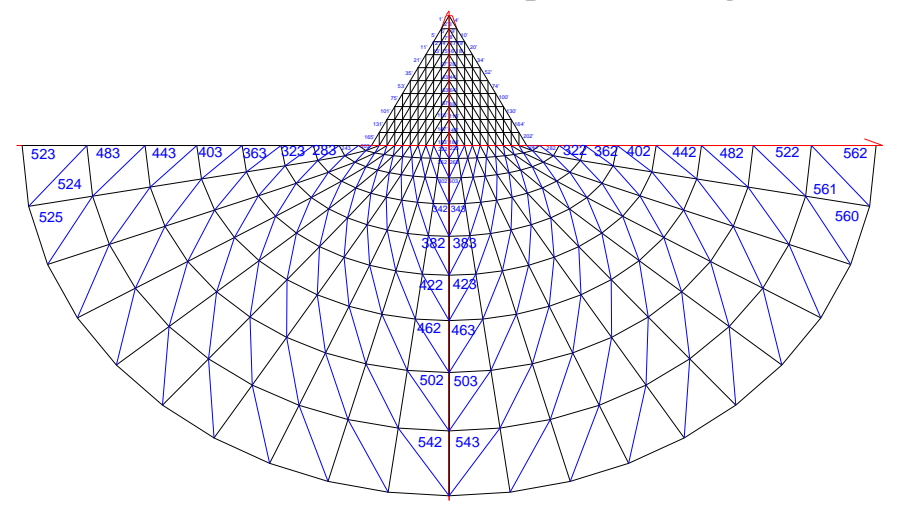

Fig. 1 finite element mesh diagram

The definition of the dam foundation and elastic modulus ratio:

$$
\beta=\frac{E_{0}}{E_{c}}
$$

Where E0 is the foundation elastic modulus, Ec is the dam elastic modulus. During the study, make the elastic modulus ratio changes from 0.25 to 10.0 , to reflect the impact of different foundation stiffness on the stress, displacement and strength criterion function.

Through the finite element calculation, the displacement of the dam and its foundation is obtained as shown in Fig. 2, shown in Fig. 3. These 3 curves is the digital code for node. Digital code on the Fig. 3 curve is the node code. It can be seen that with the increase of the foundation stiffness, the maximal displacement of the whole domain of the dam and foundation is decreasing.

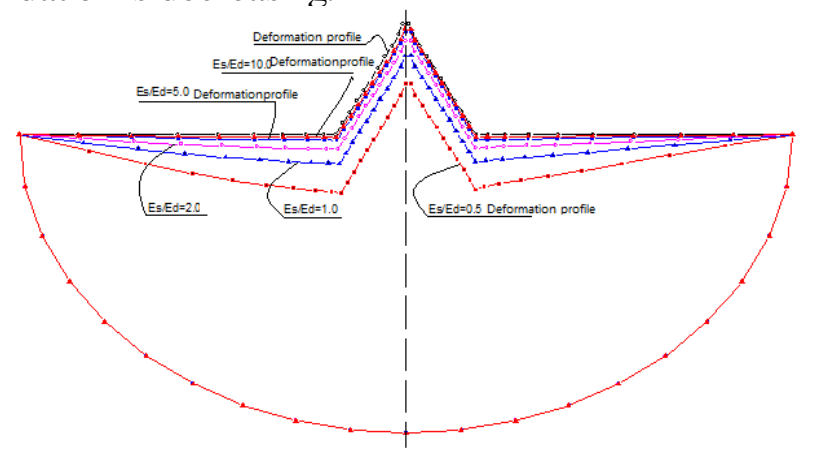

Fig. 2 Influence of elastic modulus ratio on the dam displacement

When the elastic modulus ratio $\beta<1$, the largest displacement vector is in the upstream face of the dam; and when the elastic modulus ratio $\beta 1 \geq 1$, the maximal vector displacement is in the top of the dam. When the elastic modulus ratio $\beta<4$, the maximum horizontal displacement is in the upper reaches of the river bed , when $\beta \geq 4$, the maximum horizontal displacement is at the crest. 


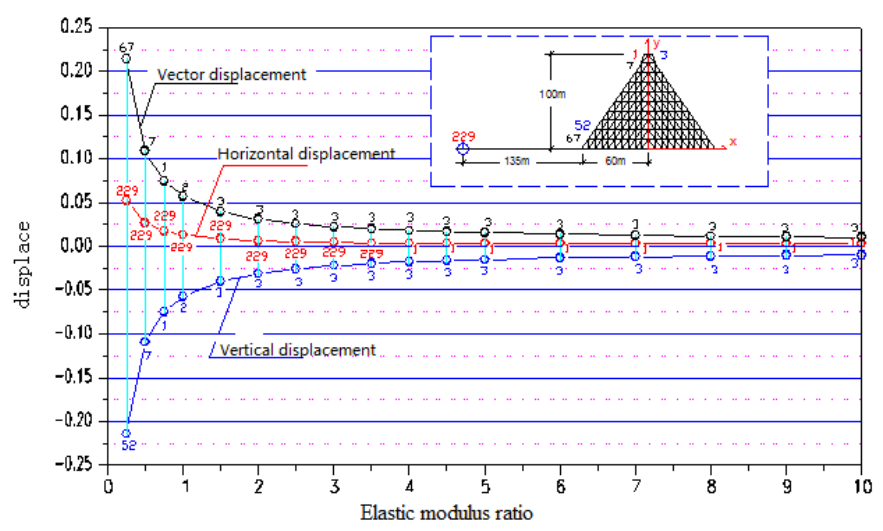

Fig. 3 Influence of elastic modulus ratio on the most value displacement

With the change in elastic modulus ratio, obtain the value and location of the value stress of dam body and foundation, as shown in Fig. 4(The number of the curve is unit code).It can be seen: the elastic modulus ratio increases, the absolute maximum values of the first and second plane principal stress reduced. That security is increased. When the elastic modulus ratio $\beta<1$, the position of the absolute maximumstress is always on the downstream toe, when $\beta=1.5$, the absolute maximum stress points is on the downstream riverbed, but close to the downstream toe of the dam, in short, the downstream toe of the dam this range is a dangerous area. When $\beta \geq 2$, the point of the absolute maximum stress deep in the riverbed the first principal stress of plane is always tensile stress, but the value is far less than the uniaxial strength index. When the elastic modulus ratio $\beta \leq 7$, the tensile stress at the downstream toe of the dam or the next downstream riverbed, when the elastic modulus ratio $\beta \geq 8$, the tensile stress at the upstream dams heel.

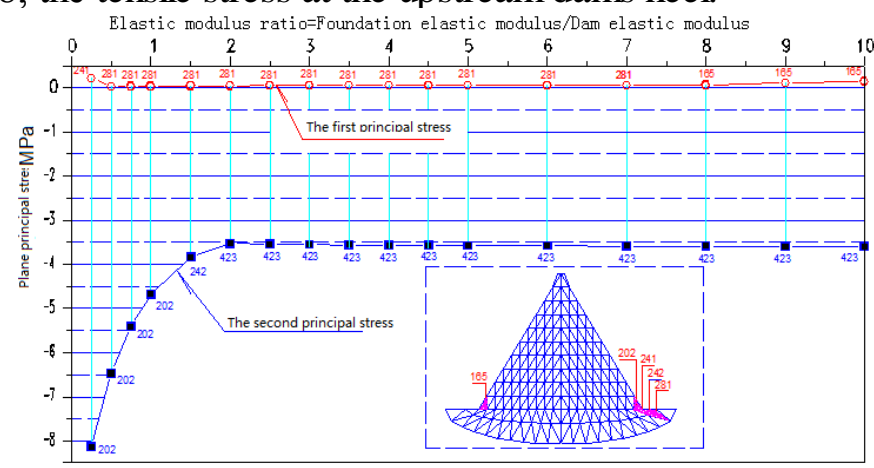

Fig. 4 Influence of elastic modulus ratio on the stress

With the change in elastic modulus ratio, obtain the value and unit location of Minimum strength criterion function of dam body and foundation, as shown in Fig. 5(The number of the curve is unit code).It can be seen that the elastic modulus ratio increases, the minimum criterion function of the whole domain is increasing. That security is increased. When the elastic modulus ratio over 7 , the minimum criterion function of the whole domain have a downward trend, but does not appear plummeted. Although view from stress, no matter what the value of elastic modulus ratio is, the maximum stress of the absolute value is compressive stress, but from the view of triaxial strength point, when the elastic modulus ratio $\beta<0.5$, the inevitable occurs destruction on the downstream dam toe .from the view of triaxial strength point, when $\beta<8$, the minimum criterion function is on the downstream dam toe, $\beta \geq 8$, the minimum criterion function on the upstream dams.

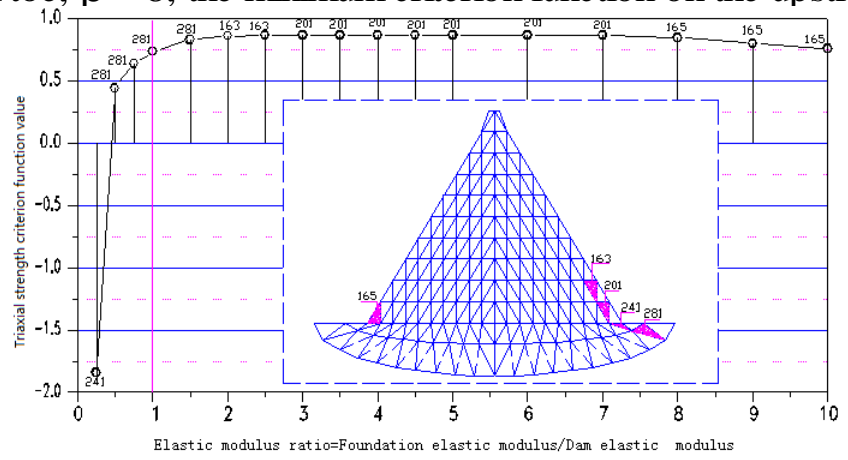

Fig. 5 Influence of elastic modulus ratio

From the above analysis, the position of the most dangerous index, some in the depths of the dam foundation, in general it is not possible to damage (because the spherical tensor of stress is small), dam deep 
point is not too concerned about the location of the project the depths location of the dam foundation is not too concerned about the project. However, the most dangerous point, most in Upstream and downstream dam feet, so it is necessary to examine the strength of these special locations .These locations can be referred to key positions, these positions indicators, to be called the key indicators. For the downstream dam site selection of 4 units, also selected 4 units for the upstream dam heel. In these selected units Plane principal stress, triaxial strength is conducted for numerical analysis to observe the influence of elastic modulus ratio on them.

\section{Conclusion}

Through the foundation and dam elastic modulus ratio, the effects of different foundation stiffness of CSG dam, the study of the CSG dam material substantially equivalent to the mechanical properties of C10 concrete materials ,the elastic modulus ratio of dam foundation and dam changes from 0.25 to 10.0 , covering the general weak rock to hard rock foundation range, from calculation results, CSG dam in this range does not the emergence the destruction phenomenon of a large area, even if the tensile stress occurs, the stress value is relatively small, so the CSG dam is very strong adaptability to the foundation.

For the different foundation, the key parts of the dam and its foundation (or dangerous parts) generally appear in the upstream and downstream toe or the depth of the foundation, according to the engineering practice can determine the downstream toe is the key part, stress analysis found that the stress value increases with the increases of the elastic modulus ratio of the foundation and dam body, but within the research scope of the foundation elastic modulus, the dam will not be destroyed.

\section{Acknowledgements}

This work was financially supported by Development plan of higher school science and technology in Shandong Province (No : J14LG03).

\section{References}

[1]Raphael. J. M. The Soil-Cement Dam[M]. University of California Berkeley, U.S.A, 1976

[2]Toshio HIROSE. Design Concept of Trapezoid-Shaped CSG dam[A]. Proceedings of the 4th International Symposium on Roller Compacted Concrete Dams[C]. 2003

[3]Jia Jinsheng, Ma Fengling, Li Xinyu, etc. gravel dam and other cementitious material properties and engineering application [J]. Hydraulic engineering, 2006, 37 (5): 578-582

[4]Yu Maohong. Engineering strength theory [M]. Beijing: Higher Education Press, 2002 